\title{
Fertility Changes in Inbred Families of Self-incompatible Chrysanthemums (Dendranthema grandiflora)
}

\author{
Neil O. Anderson ${ }^{1}$ and Peter D. Ascher ${ }^{2}$ \\ Department of Horticultural Science, University of Minnesota, 1970 Folwell Avenue, St. Paul, MN 55108
}

\begin{abstract}
AdDitional INDEX wORDs. female fertility, female sterility, inbreeding depression, male fertility, male sterility, pseudo-selfcompatibility, recombinant inbreeding

Abstract. Chrysanthemum [Dendranthema $\times$ grandiflora Tzvelv. (syn. Chrysanthemum $\times$ morifolium Ramat.)] breeding programs have been selecting for reduced expression of self-incompatibility (via pseudo-self-compatibility) to create inbred families with selected genotypes to serve as parents for $F_{1}$ hybrid chrysanthemum seed production. However, it is not known to what extent inbreeding is affecting fertility in this outcrossing, heterozygous species. The objective of this research was to assess male/female fertility changes (gain/loss) in successive inbred generations of chrysanthemums. Pseudo-self-compatible chrysanthemum parents $(n=41$ inbred, noninbred, and recombinant inbred) were chosen for fertility analyses. As many as three generations of inbreds $\left(I_{1}, I_{2}\right.$, and $\left.I_{3}\right)$ from self-pollinations were created using rapid generation cycling. Female and male fertility levels of the parents and all derived inbred populations were assessed using outcross seed set and pollen stainability, respectively. Average seed set ranges were $0.3 \%$ to $96.1 \%$ (inbred parents), $24.5 \%$ to $38.5 \%$ (noninbred parents), and $0.9 \%$ to $85.1 \%$ (recombinant inbred parents); these began decreasing in the $I_{1}$ and continued to decline steadily into the $I_{3}$. Statistically significant $(P<0.05)$ decreases in seed set occurred in $n=23$ $\mathbf{5 6 . 1 \%}$ ) inbred families; the remaining inbred families had similar or higher fertility than the parents. Pollen stainability was $>50 \%$ for the parents, but began declining in some inbred families as inbreeding progressed. Fertility reductions were attributed to inbreeding depression. Lack of significant fertility losses in other inbred families demonstrates the opportunity of selection of fertile inbred parents for use in hybrid seed production.
\end{abstract}

At least 71 plant families and 250 genera have species that possess self-incompatibility (SI) which enforces allogamy and prevents fertilization (selfs or outcrosses) when $S$ alleles, expressed in pollen and pistil, are matched (Ascher, 1976). SI is characterized as slowed growth of pollen tubes in the style (gametophytic SI) or by lack of pollen germination or stigmatic penetration (sporophytic SI). Since SI operates as a prefertilization barrier, it is one of the least expensive outcrossing mechanisms with regard to the allocation of maternal resources (Stephenson and Bertin, 1983).

SI has been viewed traditionally as an outcrossing mechanism to regulate quality of offspring by avoiding inbreeding depression (Darwin, 1876; Lande and Schemske, 1985; Winsor et al., 1987). Thus, many have equated SI with outbreeding and self-compatibility (SC) with inbreeding in natural populations (McLeod et al., 1983; Ruiz and Arroyo, 1978). It does not follow, however, that SI species be highly outbred or that SC be inbred (Kress, 1983). This is especially true since many SI systems are not based on strict identification or rejection of like pollen, but are phenotypically plastic (Stephenson and Bertin, 1983). Pseudo-self-compatibility (PSC) is an example of such plasticity and occurs in species with an active SI system, where limited to full complements of self-seed are produced. Plasticity of SI expression suggests that strict SI is only one portion of the continuum that ends with complete SC (Liedl and Anderson, 1986; 1993).

SI is disadvantageous in breeding programs when $S$ alleles are

Received for publication 11 Jan. 2000. Accepted for publication 20 June 2000 Minnesota Agricultural Experiment Station scientific journal series paper 21,265. The cost of publishing this paper was defrayed in part by the payment of page charges. Under postal regulations, this paper therefore must be hereby marked advertisement solely to indicate this fact.

${ }^{1}$ Assistant professor, to whom reprint requests should be addressed; e-mail ander044@tc.umn.edu.

${ }^{2}$ Professor. limited and/or inbred lines are being developed. Selection against SI and for PSC must occur during the inbreeding process. However, once inbred lines have been created, SI is of economic and practical importance for hybrid seed production. In this situation, two SI but cross-compatible inbreds are used as parents. These cross-compatible parents must possess high levels of fertility for commercial seed production. This may pose problems during development of inbred lines, since fertility usually declines due to inbreeding depression, and fertility and self-seed set in an SI species would not be correlated. SI is unrelated to and independent of fertility per se (Anderson et al., 1992b). While early researchers described SI as self-sterility, this is a misnomer, since pollinations between individuals without $S$ allele matches produce seed.

Garden and greenhouse chrysanthemums, [Dendranthema $\times$ grandiflora (syn. Chrysanthemum $\times$ morifolium)], are important floriculture crops, sold as vegetatively propagated cut flowers, potted plants, and herbaceous annual/perennial bedding plants (U.S. Dept. of Agriculture, 1999). Chrysanthemum breeding programs have devoted $>15$ years to selecting for PSC and creating inbred parents/families for potential $F_{1}$ hybrid seed production (Anderson and Ascher, 1996). In this allohexaploid $(2 n=6 x=54)$ crop, random outcross pollinations among unrelated, noninbred genotypes produce low seed set, ranging from $36 \%$ to $71 \%$ (Ronald, 1974 ); $<50 \%$ seed set predominates with most pollinations. A primary reason for low seed set is due to matched $S$ alleles or epistatic interactions, since $D$. grandiflora possesses a sporophytic SI system governed by more than one locus (Boase et al., 1997; Drewlow et al., 1973; Zagorski et al., 1983). Inbreeding depression and genetic load predominate in this species, due to outcrossing (SI), heterogeneity, and polyploidy (Anderson et al., 1992a, 1992b). Recombinant inbreeding-juxtaposing inbreeding with outcrossing in successive generations - partially circumvents and/or minimizes these deleteri- 
ous effects (Anderson et al., 1993). It is not known, however, whether inbreeding depression is decreasing fertility levels in PSC individuals across generations. Therefore, the objective of this research was to assess male and female fertility changes in successive inbred generations of $D$. grandiflora without the confounding effects of SI.

Table 1. Average female fertility (percentage outcross seed set) in inbred chrysanthemum populations surviving one to three generations of selfing $\left(\mathrm{I}_{1}, \mathrm{I}_{2}, \mathrm{I}_{3}\right)$.

\begin{tabular}{|c|c|c|c|c|c|c|c|}
\hline \multirow[b]{2}{*}{ Population } & \multirow{2}{*}{$\begin{array}{c}\text { Parental } \\
\text { inbreeding } \\
\text { history }^{\mathrm{x}}\end{array}$} & \multicolumn{4}{|c|}{$\begin{array}{l}\text { Uncorrected mean } \% \\
\text { outcross seed set }\end{array}$} & \multicolumn{2}{|c|}{ ANOVA $^{y}$} \\
\hline & & Parent & $\mathrm{I}_{1}$ & $\mathrm{I}_{2}$ & $\mathrm{I}_{3}$ & $\mathrm{~F}$ & $P$ \\
\hline \multicolumn{8}{|l|}{ Inbred parents } \\
\hline 81-L241-3 & 3,1 & 79.2 & 19.0 & & & 2.2 & 0.14 \\
\hline $83-76-24$ & 0,3 & 0.4 & 16.0 & & & 0.1 & 0.41 \\
\hline $83-172-2$ & 3,2 & 42.8 & 20.0 & & & 0.8 & 0.01 \\
\hline $83-263-1$ & 3,1 & 18.4 & 25.0 & & & 11.3 & $<0.001$ \\
\hline $83-263-6$ & 3,1 & 56.2 & 9.0 & & & 2.1 & 0.17 \\
\hline $84-161-17$ & 3,1 & 19.7 & 4.5 & & & 4.4 & 0.05 \\
\hline $85-92-51$ & 2,2 & 58.0 & 2.0 & & & 9.8 & 0.016 \\
\hline $85-303-1$ & 2,2 & 73.9 & 14.0 & & & 2.1 & 0.17 \\
\hline $85-303-2$ & 2,2 & 84.6 & 3.0 & & & 13.4 & 0.02 \\
\hline $85-341-4$ & 1,2 & 0.5 & 9.0 & & & 2.0 & 0.23 \\
\hline $85-341-9$ & 1,2 & 0.3 & 7.8 & & & 2.6 & 0.116 \\
\hline $79-Z 142-2$ & 3,0 & 8.0 & 15.0 & 7.4 & & 1.1 & 0.36 \\
\hline $85-92-61$ & 2,2 & 49.4 & 45.1 & 9.8 & & 7.2 & 0.003 \\
\hline $85-117-8$ & 3,3 & 53.8 & 8.0 & 4.5 & & 0.1 & 0.99 \\
\hline 77-AM3-17 & 2,0 & 82.0 & 9.5 & 20.0 & 7.8 & 11.3 & $<0.001$ \\
\hline $81-1-1$ & 1,0 & 87.7 & 25.0 & 9.0 & 15.0 & 7.3 & $<0.001$ \\
\hline 82-119-2 & 3,0 & 96.1 & 14.8 & 10.5 & 14.8 & 21.2 & $<0.001$ \\
\hline \multicolumn{8}{|l|}{ Noninbred parents } \\
\hline Centerpiece & 0,0 & 25.9 & 27.8 & & & & \\
\hline Daisy White & 0,0 & 38.5 & 2.6 & & & & \\
\hline Echo & 0,0 & 24.5 & 23.9 & & & & \\
\hline Pooled $^{\mathrm{w}}$ & & 35.0 & 9.0 & & & 3.8 & 0.073 \\
\hline \multicolumn{8}{|c|}{ Recombinant inbred parents } \\
\hline $83-263-1 \times 6$ & 3,2 & 18.4 & 9.2 & & & 3.3 & 0.08 \\
\hline $85-92-61^{\mathrm{v}} \times 51$ & 2,3 & 10.0 & 20.0 & & & 0.7 & 0.5 \\
\hline $85-312-3^{\mathrm{v}} \times 6^{\mathrm{v}}$ & 2,5 & 16.3 & 8.0 & & & 0.1 & 0.02 \\
\hline $85-341-4 \times 9$ & 1,3 & 3.9 & 4.5 & & & 7.6 & 0.02 \\
\hline AGSL-1 & 0,0 & 43.9 & 8.0 & & & 3.5 & 0.084 \\
\hline AGSL-2 & 0,0 & 85.1 & 70.0 & & & 0.7 & 0.3 \\
\hline AGSL-12 & 0,0 & 37.1 & 8.0 & & & 1.5 & 0.236 \\
\hline GLSL-2 & 0,0 & 4.9 & 15.0 & & & 3.1 & 0.121 \\
\hline GLSL-8 & 0,0 & 32.2 & 9.0 & & & 5.0 & 0.018 \\
\hline GLSL-9 & 0,0 & 41.7 & 20.0 & & & 0.9 & 0.99 \\
\hline GLSL-10 & 0,0 & 0.9 & 20.0 & & & 6.3 & 0.031 \\
\hline GLSL-12 & 0,0 & 21.1 & 17.5 & & & 0.1 & 0.99 \\
\hline PPSL-1 & 1,0 & 31.4 & 39.0 & & & 0.1 & 0.12 \\
\hline PPSL-4 & 1,0 & 60.0 & 30.0 & & & 2.5 & 0.144 \\
\hline PPSL-6 & 1,0 & 47.6 & 7.9 & & & 1.6 & 0.253 \\
\hline $84-161-28^{v} \times 17$ & 3,2 & 62.9 & 4.0 & 30.0 & & 8.2 & $<0.001$ \\
\hline PPSL-12 & 1,0 & 43.4 & 20.0 & 4.5 & & 0.9 & 0.04 \\
\hline GLSL-6 & 0,0 & 19.4 & 7.8 & 30.0 & & 21.9 & $<0.001$ \\
\hline GLSL-7 & 0,0 & 36.9 & 9.2 & 32.0 & & 7.1 & 0.009 \\
\hline PPSL-10 & 1,0 & 41.4 & 67.1 & 14.7 & 9.0 & 31.5 & $<0.001$ \\
\hline $86-N 711-1$ & 0,0 & 36.8 & 17.5 & 30.0 & 25.0 & 6.1 & $<0.001$ \\
\hline
\end{tabular}

${ }^{\mathrm{z}}$ Percentage seed set $=\left[\left(\sum\right.\right.$ no. seeds $/ \sum$ no. ovules $\left.) \times 100\right]$. There were three replications per pollination.

${ }^{y}$ Before statistical analysis, percentage seed set data were arcsine square-root transformed.

${ }^{\mathrm{x}}$ No. of generations selfed, full-sib mated. Coefficient of inbreeding (F) could not be calculated (see text). In some instances (AGSL and GLSL), the values are 0,0 since the parental inbreeding information was proprietary.

${ }^{\mathrm{w}}$ Cultivars were pooled to increase population sizes for ANOVA.

'Individual parents that were completely SI. Separate inbred families (from selfing these parents) could not be obtained for comparison with the fullsib recombinant inbred families. 


\section{Materials and Methods}

Cultural environment. Plants were grown to anthesis in 305 $\mathrm{cm}^{3}$ pots under glasshouse conditions $\left(45^{\circ} \mathrm{N}\right.$ latitude), which were maintained at $24 \pm 5^{\circ} \mathrm{C}$ days $/ 15 \pm 1^{\circ} \mathrm{C}$ nights. The growing medium consisted of 1 soil: 1 sand: 2 peat $(\mathrm{v} / \mathrm{v})$; mineral nutrient applications were based on biweekly soil tests. Routine insecticidal and fungicidal practices were followed (Anderson et al., 1990). Plants were maintained under long day conditions during the vegetative state; from 21 Sept. to 21 Mar. Long days were supplied by supplemental lighting using high intensity discharge, high pressure sodium lamps (0600 to $2200 \mathrm{HR})$. To induce flower bud initiation and development, short day photoperiods were instituted with black cloth (1600 to 0800 HR).

Plant material. Forty-one genotypes were chosen to create one to three inbred generations for fertility analyses. Included were 17 inbred parents (numbered selections with one to six generations of full-sib mating or selfing), three noninbred cultivars ('Centerpiece', 'Daisy White', and 'Echo'), and 21 recombinant inbreds (numbered selections). The level of inbreeding, i.e., number of selfed and fullsib inbred generations of all parents, is included in Table 1. Inbred parents had been propagated vegetatively since their creation as inbred genotypes; as such they were clonal replications of each respective mother plant. Conversely, the recombinant inbreds (derived from full-sib mating or intercrossing inbred families followed by selfing) had not been clonally maintained and fertility analyses proceeded on the mother plants themselves. These recombinant inbred parents were derived from juxtaposing outcrossing and inbreeding (selfing or full-sib mating) in prior successive generations of the parental pedigrees (Anderson et al., 1993; Bailey, 1971). The coefficient of inbreeding $(F)$ for these recombinant inbreds are inaccurate predictors of inbreeding depression effects, since inbreeding and outcrossing alternates between generations. $F$ values are also inadequate mathematical expressions for nonrecombinant inbreds, given the inability of the disomic or hexasomic equations to encompass all of the genetic mechanisms operating in this allohexaploid (Anderson et al., 1992b). Thus, levels of inbreeding will be presented as the number of selfed generations.

INBREEDING. To generate the inbreds, each genotype (all 41 original parents) and derived inbred families $\left(\mathrm{I}_{1}, \mathrm{I}_{2}\right.$, and $\mathrm{I}_{3}$ plants $)$ were self-pollinated. Three inflorescences/genotype (replications) were self-pollinated. Before anthesis and pollination, inflorescences were removed from each plant and placed under laboratory conditions for pollination and seed development (Anderson et al., 1990). All viable embryos were embryo rescued, germinated, and grown in vitro until true-leaf stage, whereupon seedlings were transplanted and grown in the greenhouse. Since chrysanthemum have composite inflorescences, each replication had $>50$ ovules/ inflorescence (Anderson et al., 1988). Inbred seed from all selfpollinations was germinated and progeny were grown to anthesis for self-pollination and fertility analyses. In every inbred generation, each individual inbred genotype within an inbred family was selfpollinated to create the next generation.

As many as three generations of inbreds $\left(I_{1}, I_{2}\right.$, and $\left.I_{3}\right)$ from selfpollinations were derived from the 41 parents, using rapid generation cycling techniques of laboratory seed ripening and embryo rescue (Anderson et al., 1990). Where possible, barring interference from SI or inbreeding depression, three successive inbred generations were produced in $<1$ year (average generation time $<100 \mathrm{~d}, 758$ genotypes). If inbreeding increases genotypic sensitivity, genotype $\times$ environment interactions $(\mathrm{G} \times \mathrm{E})$ could grossly inflate the divergence in mean phenotypes (Lynch, 1988). Use of uniform crossing conditions (laboratory seed ripening) minimized variation due to $\mathrm{G}$ $\times$ E (Anderson et al., 1990).

Fertility ASSESSMENT. Female fertility of each parent and their inbred families ( $\mathrm{I}_{1}, \mathrm{I}_{2}$, and $\mathrm{I}_{3}$ generations) was assessed by using a composite bulk of parental pollen (Maletsky and Weisman, 1978). The composite bulk was on a volume basis and pollen was obtained from inflorescences using a Mach I vacuum-assisted pollen collector (Dave Olson, St. Paul, Minn.). The bulk outcross pollination was used as the best possible estimator of female fertility since there should be no confounding of seed set reduction with matched $S$ alleles (Anderson et al., 1990). Before anthesis and emasculation, inflorescences were removed from the maternal parent; all pollinations were performed under the identical laboratory conditions (rapid generation cycling) used for inbreeding. This minimized most source/sink influences with the maternal parent (Anderson et al., 1990). Three emasculated inflorescences (replications), with only the gynoecious ray florets remaining, were pollinated for each genotype. Since the number of potential ovules varies between inflorescences and within/between clonal genotypes and flower types (single daisy to fully double), ovules were counted (Anderson et al., 1988). The numbers of ovules and seed set were recorded when embryogenesis had progressed past heart-stage embryos. At this point, seedcoat coloration has been deposited and seeds with developing embryos are easily distinguished from unfertilized ovules. Percent seed set was then calculated. Genotypes that failed to flower, those with deformed ovules, or those that did not produce seeds with outcross pollinations were classed as complete female steriles.

Male fertility of plants reaching anthesis (pollen shed) was established using pollen stainability (Owczarzak, 1952). Pollen was collected from more than one flower per genotype and stained with $0.1 \%$ aniline blue in $80 \%$ propionic acid (Anderson and Ascher, 1993; E.B. Smith, personal communication, 1989). Five microscope fields (replications) with $\mathrm{n} \geq 20$ grains/field were assessed per genotype for percentage pollen stainability. Only those genotypes with $0 \%$ stainable pollen, deformed anthers or lack thereof, and/or those with anthers failing to dehisce were classified as complete male steriles (Knuth and Rose, 1989). Pollen stainability per se is only used as an indicator of male fertility since pollen viability is not a guarantor of germination, pollen tube growth, and/or double fertilization. Thus, male fertility in this study is a measurement of viable male gamete formation.

Data Collection and analysis. Percentage seed set and pollen stainability data were arcsine square-root transformed before analysis (Levin, 1984). Fertility data were analyzed for significant variation across inbred generations using unbalanced analysis of variance (ANOVA), due to the variable number of progeny across generations. Linear regression was performed for female and male fertility values against the inbred generation.

\section{Results}

Average percentage seed set ranges (female fertility) were $0.3 \%$ to $96.1 \%$ for inbred parents, $24.5 \%$ to $38.5 \%$ for noninbred parents, and $0.9 \%$ to $85.1 \%$ for recombinant inbred parents (Table 1 ). Most fell between $16.3 \%$ and $82 \%$, regardless of the parent group. Female fertility levels began decreasing in the $\mathrm{I}_{1}$ (overall range was $2.0 \%$ to $70.0 \%)$ and continued to decline steadily to the $\mathrm{I}_{3}(7.8 \%$ to $25.0 \%)$. Statistically significant $(P<0.05)$ changes in seed set occurred in some $(56.1 \%)$, but not all, inbred families (Table 1). The high variability between plants within inbred families for fertility, as well as inbred family size affected these results. In a few instances, the 
fertility levels increased significantly in the $\mathrm{I}_{1}$ when compared to the parents, e.g., 85-341-9, 79-Z142-2, 83-263-1, and PPSL-10. If, however, additional inbred generations were obtained, the values typically dropped to lower levels than the parent. High levels of seed set percentages did not necessarily predicate tolerance to inbreeding depression, e.g., 85-303-2 (84.6\%) survived only one generation of inbreeding while 79-Z142-2 (8.0\%) produced an additional inbred generation (Table 1). Lack of survival to create additional inbred generations was due to various inbreeding depression factors, i.e., low/no seed germination, decreased vigor, lack of survival after transplanting, nonflowering genotypes (Anderson et al., 1992b).

The slope of the lines and correlation $(r)$ values for linear regression of female fertility values (data not presented) were predominantly negative. Correlations and $Y$ intercepts varied widely and were not correlated with the number of inbred generations produced by any parent (Table 1).

Pollen stainability averaged above $50 \%$ for the parents $(59.8 \%$ to $98.8 \%$ ) and began declining in some inbred families as inbreeding

Table 2. Average male fertility (percentage pollen stainability) in inbred chrysanthemum populations surviving one to three generations of selfing $\left(\mathrm{I}_{1}, \mathrm{I}_{2}, \mathrm{I}_{3}\right)$.

\begin{tabular}{|c|c|c|c|c|c|c|}
\hline \multirow[b]{2}{*}{ Population } & \multicolumn{4}{|c|}{$\begin{array}{l}\text { Uncorrected mean } \% \\
\text { pollen stainability }^{z}\end{array}$} & \multicolumn{2}{|c|}{ Significance $^{\mathrm{y}}$} \\
\hline & Parent & $\mathrm{I}_{1}$ & $\mathrm{I}_{2}$ & $\mathrm{I}_{3}$ & $\mathrm{~F}$ & $P$ \\
\hline \multicolumn{7}{|l|}{ Inbred parents } \\
\hline 81-L241-3 & 97.2 & 75.9 & & & 2.4 & 0.124 \\
\hline $83-76-24$ & 74.5 & 77.8 & & & 2.3 & 0.14 \\
\hline $83-172-2$ & 98.8 & 78.4 & & & 2.4 & 0.13 \\
\hline $83-263-1$ & 89.8 & 78.6 & & & 52.4 & $<0.001$ \\
\hline $83-263-6$ & 86.7 & 85.1 & & & 1.5 & 0.239 \\
\hline $84-161-17$ & 92.1 & 71.4 & & & 5.8 & 0.02 \\
\hline $85-92-51$ & 83.2 & 76.8 & & & 0.7 & 0.978 \\
\hline $85-303-1$ & 64.2 & 79.0 & & & 15.2 & $<0.001$ \\
\hline $85-303-2$ & 97.2 & 77.0 & & & 35.8 & $<0.001$ \\
\hline $85-341-4$ & 92.1 & 89.8 & & & 3.4 & 0.1 \\
\hline $85-341-9$ & 78.2 & 70.9 & & & 0.5 & 0.9 \\
\hline 79-Z142-2 & 95.3 & 84.2 & 57.5 & & 1.6 & 0.22 \\
\hline $85-92-61$ & 81.3 & 66.5 & 60.5 & & 3.5 & 0.028 \\
\hline $85-117-8$ & 80.6 & 84.4 & 84.8 & 82.5 & 4500.8 & $<0.001$ \\
\hline 77-AM3-17 & 83.4 & 83.5 & 69.7 & 58.4 & 4.9 & 0.002 \\
\hline $81-1-1$ & 83.6 & 88.6 & 82.2 & 65.0 & 81.9 & $<0.001$ \\
\hline 82-119-2 & 96.6 & 81.9 & 56.0 & 82.4 & 20.9 & $<0.001$ \\
\hline \multicolumn{7}{|l|}{ Noninbred parents } \\
\hline Cultivars ${ }^{\mathrm{x}}$ & 79.7 & 70.1 & & & 7.7 & 0.01 \\
\hline \multicolumn{7}{|c|}{ Recombinant inbred parents } \\
\hline $83-263-1 \times 6$ & 88.2 & 78.5 & & & 2.9 & 0.09 \\
\hline $85-92-61 \times 51$ & 79.6 & 68.0 & & & 7.3 & 0.014 \\
\hline $85-312-3 \times 6$ & 78.1 & 79.8 & & & 0.8 & 0.21 \\
\hline $85-341-4 \times 9$ & 85.2 & 77.7 & & & 1.6 & 0.22 \\
\hline AGSL-1 & 80.6 & 78.9 & & & 3.8 & 0.064 \\
\hline AGSL-2 & 97.8 & $<0.1$ & & & 45.2 & $<0.001$ \\
\hline AGSL-12 & 67.8 & 83.3 & & & 2.0 & 0.16 \\
\hline GLSL-2 & 86.1 & 85.2 & & & 0.02 & 0.99 \\
\hline GLSL-8 & 96.6 & 74.1 & & & 2496.2 & $<0.001$ \\
\hline GLSL-9 & 95.3 & 84.9 & & & 11.6 & 0.009 \\
\hline GLSL-10 & 89.4 & 84.1 & & & 0.3 & 0.96 \\
\hline GLSL-12 & 78.9 & 80.8 & & & 2.2 & 0.16 \\
\hline PPSL-1 & 75.7 & 78.7 & & & 0.6 & 0.99 \\
\hline PPSL-4 & 86.8 & 89.4 & & & 3.9 & 0.064 \\
\hline PPSL-6 & 89.8 & 93.4 & & & 4.2 & 0.061 \\
\hline $84-161-28 \times 17$ & 89.5 & 72.2 & 63.0 & & 1.3 & 0.282 \\
\hline PPSL-12 & 89.4 & 83.1 & 85.5 & & 2.9 & 0.056 \\
\hline GLSL-6 & 89.6 & 86.2 & 80.7 & & 281.0 & $<0.001$ \\
\hline GLSL-7 & 86.5 & 85.8 & 83.0 & & 53.8 & $<0.001$ \\
\hline PPSL-10 & 96.9 & 79.8 & 82.7 & 54.0 & 20.1 & $<0.001$ \\
\hline 86-N711-1 & 59.8 & 84.7 & 84.6 & 77.8 & 2.9 & 0.03 \\
\hline
\end{tabular}

${ }^{\mathrm{z}}$ Minimum population size for percentage pollen stainability, $\mathrm{n} \geq 100$ pollen grains. Counts consisted of five microscope fields with $\mathrm{n} \geq 20$ pollen grains per field.

'Before statistical analysis, percentage pollen stainability data were arcsine square-root transformed.

'Named cultivars were pooled; these included 'Centerpiece', 'Daisy White', and 'Echo'. 
progressed (Table 2). However, in most cases pollen stainability remained $>50 \%$ in the more advanced inbred generations $\left(\mathrm{I}_{2}\right.$ to $\left.\mathrm{I}_{3}\right)$. This would indicate that, while inbreeding depression may have been causing some reduction in the proportion of viable pollen grains, it was not adversely affecting male fertility such that the individuals could not effect fertilization. Reductions in male fertility within families was frequently significant, regardless of the number of inbred generations produced. For instance, the reduction in male fertility was as significant with 83-263-1 $(P<0.001)$, which lasted only through $\mathrm{I}_{1}$, as 82-119-2, which generated $\mathrm{I}_{3}$ inbreds $(P<0.001)$. When comparing the significance of the reduction between female and male fertility, the responses were predominantly the same (either nonsignificant or significant). In several instances, however, the responses were the opposite, that is nonsignificant for female and significant for male (85-303-1, 85-117-8, 85-92-61 x 51, AGSL2, GLSL-9, PPSL-4 and 6) or vice versa (85-312-3 x 6, 85-341-

Table 3. Frequency of complete male or female sterile progeny of inbred chrysanthemum lines derived from one to three generations of selfing $\left(\mathrm{I}_{1}\right.$, $\left.\mathrm{I}_{2}, \mathrm{I}_{3}\right)$.

\begin{tabular}{|c|c|c|c|c|c|c|c|c|c|c|c|c|c|c|c|c|c|c|}
\hline \multirow[b]{3}{*}{ Population } & \multicolumn{9}{|c|}{ Male sterility (MS) } & \multicolumn{9}{|c|}{ Female sterility (FS) } \\
\hline & \multicolumn{3}{|c|}{$\mathrm{I}_{1}$} & \multicolumn{3}{|c|}{$\mathrm{I}_{2}$} & \multicolumn{3}{|c|}{$\mathrm{I}_{3}$} & \multicolumn{3}{|c|}{$\mathrm{I}_{1}$} & \multicolumn{3}{|c|}{$\mathrm{I}_{2}$} & \multicolumn{3}{|c|}{$\mathrm{I}_{3}$} \\
\hline & MS & No. & $\%$ & MS & No. & $\%$ & MS & No. & $\%$ & FS & No. & $\%$ & FS & No. & $\%$ & FS & No. & $\%$ \\
\hline \multicolumn{19}{|l|}{ Inbred parents } \\
\hline 81-L241-3 & 1 & 17 & 5.9 & & & & & & & 1 & 17 & 5.9 & & & & & & \\
\hline $83-76-24$ & 2 & 10 & 20.0 & & & & & & & 0 & 10 & 0.0 & & & & & & \\
\hline $83-172-2$ & 3 & 13 & 23.1 & 0 & 2 & 0.0 & & & & 0 & 13 & 0.0 & 0 & 2 & 0.0 & & & \\
\hline $83-263-1$ & 0 & 19 & 0.0 & 1 & 3 & 33.3 & & & & 1 & 19 & 5.3 & 1 & 3 & 33.3 & & & \\
\hline $83-263-6$ & 0 & 4 & 0.0 & 0 & 3 & 0.0 & & & & 0 & 4 & 0.0 & 0 & 3 & 0.0 & & & \\
\hline $84-161-17$ & 0 & 8 & 0.0 & & & & & & & 2 & 8 & 25.0 & & & & & & \\
\hline $85-92-51$ & 0 & 3 & 0.0 & & & & & & & 1 & 3 & 33.3 & & & & & & \\
\hline $85-303-1$ & 0 & 4 & 0.0 & 0 & 1 & 0.0 & & & & 0 & 4 & 0.0 & 0 & 1 & 0.0 & & & \\
\hline $85-303-2$ & 0 & 1 & 0.0 & & & & & & & 0 & 1 & 0.0 & & & & & & \\
\hline $85-341-4$ & 0 & 2 & 0.0 & & & & & & & 0 & 2 & 0.0 & & & & & & \\
\hline $85-341-9$ & 1 & 13 & 7.7 & & & & & & & 1 & 13 & 7.7 & & & & & & \\
\hline $79-Z 142-2$ & 2 & 7 & 28.6 & 0 & 8 & 0.0 & & & & 0 & 7 & 0.0 & 1 & 8 & 12.5 & & & \\
\hline $85-92-61$ & 0 & 1 & 0.0 & 0 & 3 & 0.0 & 1 & 3 & 33.3 & 0 & 1 & 0.0 & 0 & 3 & 0.0 & 1 & 3 & 33.3 \\
\hline $85-117-8$ & 0 & 3 & 0.0 & 1 & 2 & 50.0 & & & & 1 & 3 & 33.3 & 0 & 2 & 0.0 & & & \\
\hline 77-AM3-17 & 3 & 9 & 33.3 & 0 & 5 & 0.0 & 2 & 10 & 20.0 & 0 & 9 & 0.0 & 0 & 5 & 0.0 & 4 & 10 & 40.0 \\
\hline $81-1-1$ & 0 & 2 & 0.0 & 5 & 45 & 11.1 & 29 & 43 & 67.4 & 0 & 2 & 0.0 & 12 & 45 & 26.7 & 6 & 43 & 13.9 \\
\hline 82-119-2 & 8 & 42 & 19.0 & 4 & 27 & 14.8 & 14 & 38 & 36.8 & 0 & 42 & 0.0 & 2 & 27 & 7.4 & 4 & 38 & 10.5 \\
\hline \multicolumn{19}{|l|}{ Noninbred parents } \\
\hline Cultivars & 0 & 4 & 0.0 & & & & & & & 0 & 4 & 0.0 & & & & & & \\
\hline \multicolumn{19}{|c|}{ Recombinant inbred parents } \\
\hline 83-263-1 x 6 & 0 & 7 & 0.0 & & & & & & & 0 & 7 & 0.0 & & & & & & \\
\hline $85-92-61 \times 51$ & 0 & 3 & 0.0 & & & & & & & 0 & 3 & 0.0 & & & & & & \\
\hline $85-312-3 \times 6$ & 0 & 4 & 0.0 & & & & & & & 0 & 4 & 0.0 & & & & & & \\
\hline $85-341-4$ × 9 & 0 & 3 & 0.0 & & & & & & & 0 & 3 & 0.0 & & & & & & \\
\hline AGSL-1 & 1 & 4 & 25.0 & & & & & & & 1 & 4 & 25.0 & & & & & & \\
\hline AGSL-2 & 2 & 4 & 50.0 & & & & & & & 0 & 4 & 0.0 & & & & & & \\
\hline AGSL-12 & 1 & 7 & 14.3 & & & & & & & 1 & 7 & 14.3 & & & & & & \\
\hline GLSL-2 & 0 & 2 & 0.0 & & & & & & & 0 & 2 & 0.0 & & & & & & \\
\hline GLSL-8 & 0 & 5 & 0.0 & 1 & 1 & 100.0 & & & & 0 & 5 & 0.0 & 1 & 1 & 100.0 & & & \\
\hline GLSL-9 & 0 & 2 & 0.0 & & & & & & & 0 & 2 & 0.0 & & & & & & \\
\hline GLSL-10 & 0 & 3 & 0.0 & & & & & & & 0 & 3 & 0.0 & & & & & & \\
\hline GLSL-12 & 0 & 4 & 0.0 & & & & & & & 0 & 4 & 0.0 & & & & & & \\
\hline PPSL-1 & 0 & 19 & 0.0 & & & & & & & 0 & 19 & 0.0 & & & & & & \\
\hline PPSL-4 & 1 & 3 & 33.3 & & & & & & & 0 & 3 & 0.0 & & & & & & \\
\hline PPSL-6 & 1 & 5 & 20.0 & & & & & & & 0 & 5 & 0.0 & & & & & & \\
\hline $84-161-28 \times 17$ & 1 & 10 & 10.0 & 1 & 7 & 14.3 & & & & 2 & 10 & 20.0 & 0 & 7 & 0.0 & & & \\
\hline PPSL-12 & 10 & 33 & 30.3 & 1 & 2 & 50.0 & & & & 7 & 33 & 21.2 & 0 & 2 & 0.0 & & & \\
\hline GLSL-6 & 3 & 80 & 3.8 & 7 & 13 & 53.8 & & & & 2 & 80 & 2.5 & 3 & 13 & 23.1 & & & \\
\hline GLSL-7 & 0 & 4 & 0.0 & 1 & 5 & 20.0 & & & & 0 & 4 & 0.0 & 1 & 5 & 20.0 & & & \\
\hline PPSL-10 & 0 & 4 & 0.0 & 1 & 14 & 7.1 & 13 & 57 & 22.8 & 0 & 4 & 0.0 & 0 & 14 & 0.0 & 16 & 57 & 28.1 \\
\hline 86-N711-1 & 10 & 36 & 27.8 & 0 & 12 & 0.0 & 9 & 64 & 14.1 & 0 & 36 & 0.0 & 0 & 12 & 0.0 & 5 & 64 & 7.8 \\
\hline Pooled & 50 & 404 & 12.4 & 23 & 153 & 15.0 & 68 & 215 & 31.6 & 20 & 404 & 5.0 & 21 & 153 & 13.7 & 36 & 215 & 16.7 \\
\hline
\end{tabular}


4 × 9, GLSL-10, 84-161-28 x 17) (Tables 1 and 2). Linear regressions of male fertility (data not presented) were similar to those for female fertility, where additional inbred generations increased the likelihood of a significant regression. Only 86-N711-1, which produced $\mathrm{I}_{1}$ to $\mathrm{I}_{3}$ generations, did not have a negative slope or $r$ value, nor did it show significant reductions in male fertility.

Inbreeding tended to produce more complete male- than female-sterile individuals (Table 3). Overall percentages of pooled complete male sterile individuals from all inbred families were $12.4 \%(\mathrm{n}=404)$ in the $\mathrm{I}_{1}, 15 \%(\mathrm{n}=153)$ for $\mathrm{I}_{2}$, and $31.6 \%(\mathrm{n}=215)$ in the $\mathrm{I}_{3}$. There were only $5 \%$ complete female steriles in the $\mathrm{I}_{1}$, $13.7 \%$ for $I_{2}$, and $16.7 \%$ for $I_{3}$. The difference in frequency between complete male and female steriles does not match the general trend observed for percentage seed set and percentage pollen stainability. Lack of complete male or female steriles in the $\mathrm{I}_{1}$ generation did not necessarily predicate that further inbred generations would be produced. For example, 81-1-1 and 84-16117 both had $0 \%$ male and female steriles in the $\mathrm{I}_{1}$ yet only $81-1$ 1 produced additional inbred generations (Table 3 ).

\section{Discussion}

$S$ allele action in SI inbred plants is only one factor involved in seed production (Maletsky and Weisman, 1978). SI and seed set (fertility) are two different, but not necessarily mutually exclusive, biological phenomena (Haruta, 1966). Hill (1976) noted that cross-pollinated, SI perennial alfalfa appeared to become increasingly more SI with continued inbreeding, due to matched $S$ alleles among full-sibs. Such was also the case with red clover (Trifolium pratense L.) (Taylor et al., 1970), alfalfa (Medicago sativa L.) (Obajimi and Bingham, 1973), and sweetpotato (Ipomoea batatas Poir) (Martin, 1972) where $I_{1}$ crosscompatible seed set was less than in most of the parents. In previous studies with chrysanthemums, those genotypes which set abundant self-seed were not necessarily cross-compatible with all genotypes even if the testers were noninbred (Ronald, 1974). Bulk pollinations were the best way to avoid this problem in the present study.

In SC species, the major barriers to obtaining highly crosscompatible inbreds, created by self-pollinations, are random drift and rapid fixation of genes that overpower selection pressures (Cornelius and Dudley, 1974). SI species, however, possess additional barriers that significantly reduce the probability of obtaining fertile inbreds upon which to exercise selection. In any inbred generation, percentage self-seed set would grossly overestimate or underestimate the effect of SI. Zero percentage self-seed set could easily be construed as a tight SI system when, in fact, it could be caused by reduced fertility. Thus, percentage self-seed set cannot be used as the sole measure of the breakdown or stability of the SI system.

Differences in performance between inbred progeny derived from full-sib mating or selfing the same parents were variable in the present study. In three cases either or both of the parents used in full-sib mating were completely SI (85-92-61, 85-312-3, 85312-6, and 84-161-28) and eliminated from Tables 1 and 2. In only one case (84-161-28 x 17) did the full-sib-derived progeny survive additional inbred generations than their selfed counterparts. Progeny were produced in all cases of full-sib mating presented herein, although their tolerance of inbreeding depression was not necessarily greater than selfed progenies (Tables 1 and 2). Thus, while full-sib mating is an important method for circumventing SI, it rarely can stave off complete extinction caused by inbreeding depression.

Occurrence of inbreeding depression in the first three inbred generations, as measured by fertility losses, was not unexpected in an allohexaploid with a highly expressed SI system (Anderson et al., 1992b). However, it is interesting to note that significant reductions in fertility did not necessarily predispose the inbred populations to extinction. For instance, there were sufficient numbers of individuals in the PPSL-10 inbred family without lethal or sublethal phenotypes such that four inbred generations were produced. This occurred despite the highly significant decrease in female fertility $(P<0.001$, Table 1$)$; the mean outcross seed set decreased from $41.1 \%$ (parent) to $9 \%$ by the $\mathrm{I}_{3}$. Another inbred family (81-1-1), which had significant reductions in both male $(P<0.001$, Table 2$)$ and female $(P<0.0001$, Table 1 ) fertility also produced fertile progeny in the $I_{3}$. Since PPSL-10 is a recombinant inbred it is possible that this genotype has a unique allelic configuration or fixed heterozygosity that may allow for the partial negation of recessive allelic expression (Haufler and Soltis, 1986; Soltis, 1986).

The occurrence of inbred families with nonsignificant reductions in fertility, when compared with the parental genotypes, demonstrates it is possible to select for unchanged or increased male/ female fertility. For instance, inbred families 83-263-1, 85-341-4, 85-341-9, 79-Z142-2, 'Centerpiece', 'Echo', 85-92-61 x 51, PPSL1 , and PPSL-10 had increased or similar female fertility levels in the $I_{1}$ (Table 1). Several of these inbred families tolerated more than one generation of inbreeding. Thus, we were able to obtain fertile genotypes for potential use as inbred parents for the creation of $F_{1}$ hybrids.

The predominance of negative linear regressions and $r$ values would be an indication that inbreeding depression is adversely affecting female fertility. Therefore, the expectation would be that those inbred families producing the least number of inbred generations would have the most negative correlation values and slopes. Correspondingly, those inbred families with more inbred generations must have female fertility that is impervious to inbreeding depression, with $r$ values and slopes nearly zero and positive, respectively. In addition, inbred families with the same number of inbred generations should have comparable $r$ values. This expectation does not hold for all cases. For instance, when comparing between families surviving three inbred generations, the linear regression for PPSL-10 is highly significant $(r=-0.27, P<0.001)$ while inbreeding has less of an effect on fertility in 81-1-1 $(r=-$ $0.11, P=0.09)$.

Classic statistical methods (ANOVA, correlation, and regression) for analysis of the effects of inbreeding depression on fertility can only imply trends (Bertin, 1982; Levin, 1984). As discussed earlier with the PPSL-10 and 81-1-1 inbred families, statistically significant reductions in fertility did not lead to extinction of the populations. However, even with low fertility levels, one zygote, possessing the genetic combinations necessary to tolerate inbreeding, can be the conduit for gene flow into the next inbred generation. Since statistical significance did not translate into biological significance, the value of such statistical tests becomes questionable. Previous research has shown that it is not possible to calculate levels of genetic load (Anderson et al., 1992a) or coefficients of inbreeding (Anderson et al., 1992b) for this allohexaploid species, due to the inherent inability of the equations to encompass the myriad of gene action in operation. Such would also be the case when extrapolating fertility levels to measure tolerance to inbreeding depression. Moreover, such tests cannot separate inbreeding depression into its respective components (male and female sterility, etc.), neither can 
they demarcate sterilities that are independent of the inbreeding process per se caused by acentric fragments or bridges (due to homoeologous pairing), fixed heterozygosity, or the accumulation of deleterious mutations. Apparent sterilities due to cross-incompatible reactions also could not be separated from inbreeding depression. Other methods can determine the existence of several, but not all, of these phenomena. For example, cytological analyses would be necessary to confirm the occasional deactivation of homologous pairing mechanism(s) while allozyme or RFLP analysis can address fixed heterozygosity and diploidization (Haufler, 1987; Haufler and Soltis, 1986; Soltis, 1986; Watanabe, 1977a, 1977b; Wolff et al., 1994).

Both the maternal and zygotic genomes have an impact on fertility levels and inbreeding depression in inbreds (Fowler, 1965; Obajimi and Bingham, 1973). In cases where pollen tube growth, double fertilization, and embryogenesis occur in situ, it would not be possible to distinguish between maternal and zygotic components of either fertility or inbreeding depression. The effects of maternal inbreeding depression, source/sink interactions, and/or plant stresses were minimized in the present study with the implementation of rapid generation cycling techniques (Anderson et al., 1990). Thus, most fertility changes realized across inbred generations of chrysanthemum arose from inbreeding depression. Additionally, the use of bulk pollinations to measure outcross seed set (female fertility) minimized the confounding effects of SI as inbreeding progressed. While fertility changes, both positive and negative, varied widely between inbred families, one to three inbred generations were realized. In the case of 85-117-8, a sixth generation inbred from selfing/full-sib mating (Table 1), two additional inbred generations were created. This is the first report of an advanced chrysanthemum inbred line with eight generations of inbreeding. While these advanced inbreds often had lowered fertility levels, this study demonstrates that it was possible to select fertile inbreds for use as parents in the creation of $F_{1}$ hybrid, seed-propagated chrysanthemums.

\section{Literature Cited}

Anderson, N.O. and P.D. Ascher. 1993. Male and female fertility of loosestrife (Lythrum) cultivars. J. Amer. Soc. Hort. Sci. 118:851-858.

Anderson, N.O. and P.D. Ascher. 1996. Inheritance of pseudo-self compatibility in self-incompatible garden and greenhouse chrysanthemums, Dendranthema grandiflora Tzvelv. Euphytica 87:153-164.

Anderson, N.O., P.D. Ascher, and J.J. Luby. 1993. Variations of recombinant inbreeding: Circumventing inbreeding depression in chrysanthemum populations, p. 1-16. In: K.K. Dhir and T.S. Sareen (eds.). Frontiers in plant science research. Bhagwati Enterprises, Delhi.

Anderson, N.O., P.D. Ascher, and R.E. Widmer. 1992a. Lethal equivalents and genetic load. Plant Breeding Rev. 10:93-127.

Anderson, N.O., P.D. Ascher, and R.E. Widmer. 1992b. Inbreeding depression in garden and glasshouse chrysanthemums: Germination and survivorship. Euphytica 62:155-169.

Anderson, N.O., P.D. Ascher, R.E. Widmer, and J.J. Luby. 1990. Rapid generation cycling of chrysanthemum using laboratory seed development and embryo rescue techniques. J. Amer. Soc. Hort. Sci. 115:329-336.

Anderson, N.O., B.E. Liedl, P.D. Ascher, R.E. Widmer, and S.L. Desborough. 1988. Evaluating self-incompatibility in Chrysanthemum. The influence of ovule number. Sexual Plant Reprod. 1:173-181.

Ascher, P.D. 1976. Self incompatibility systems in floricultural crops. Acta Hort. 63:205-215.

Bailey, D.W. 1971. Recombinant-inbred strains: An aid to finding identity, linkage, and function of histocompatibility and other genes. Transplantation 11:325-327.

Bertin, R.I. 1982. Paternity and fruit production in trumpet creeper (Campsis radicans). The Amer. Nat. 119:694-709.

Boase, M.R., R. Miller, and S.C. Deroles. 1997. Chrysanthemum systematics, genetics, and breeding. Plant Breeding Rev. 14:321-361.

Cornelius, P.L. and J.W. Dudley. 1974. Effects of inbreeding by selfing and fullsib mating in a maize population. Crop Sci. 14:815-819.

Darwin, C.R. 1876. The effect of cross- and self-fertilization in the vegetable kingdom. John Murray, London.

Drewlow, L.W.,P.D. Ascher, and R.E. Widmer. 1973. Rapid method of determining pollen incompatibility in Chrysanthemum morifolium Ramat. Theor. Appl. Genet. 43:1-5.

Fowler, D.P. 1965. Effects of inbreeding in red pine, Pinus retinosa Ait. II. Pollination studies. Silvae Genetica 14:12-23.

Haruta, T. 1966. Studies on the genetics of self- and cross-incompatibility in cruciferous vegetables. Northrup King and Co., Minneapolis, Minn.

Haufler, C.H. 1987. Electrophoresis is modifying our concepts of evolution in homosporous pteridophytes. Amer. J. Bot. 74:953-966.

Haufler, C.H. and D.E. Soltis. 1986. Genetic evidence suggests that homosporous ferns with high chromosome numbers are diploid. Proc. Amer. Acad. Sci. 83:4389-4393.

Hill, R.R. 1976. Response to inbreeding in alfalfa populations derived from single clones. Crop Sci. 16:237-241.

Knuth, M. and M. Rose. 1989. Untersuchungen zur Bestimmung der Pollenvitalitaet bei Chrysanthemen und Edelnelken. Archiv fuer Gartenbau, Berlin 37:335343.

Kress, W.J. 1983. Self-incompatibility in Central American Heliconia. Evolution 37:735-744.

Lande, R. and D.W. Schemske. 1985. The evolution of self-fertilization and inbreeding depression in plants. I. Genetic models. Evolution 39:24-40.

Levin, D.A. 1984. Inbreeding depression and proximity-dependent crossing success in Phlox drummondii. Evolution 38:116-127.

Liedl, B.E. and N.O. Anderson. 1986. Incompatibility hermeneutics: The determination of cutoff values. Plant Cell Inc. Nwsl. 18:6-12.

Liedl, B.E. and N.O. Anderson. 1993. Reproductive barriers: Identification, uses, and circumvention. Plant Breeding Rev. 11:11-154.

Lynch, M. 1988. Design and analysis of experiments on random drift and inbreeding depression. Genetics 120:791-807.

Maletsky, S.I. and N.J. Weisman. 1978. A population genetic analysis of self- and cross-incompatibility in sugar beet (Beta vulgaris L.). Theor. Appl. Genet. $52: 21-28$.

Martin, F.W. 1972. Inheritance of self-incompatibility versus self-fertility in the sweetpotato. Incompatibility Nwsl. 1:17-19.

McLeod, M.J., S.I. Guttman, W.H. Eschbaugh, and R.E. Rayle. 1983. An electrophoretic study of evolution in Capsicum (Solanaceae). Evolution 37:562-574.

Obajimi, A.O. and E.T. Bingham. 1973. Inbreeding cultivated alfalfa in one tetraploid-haploid-tetraploid cycle: Effects on morphology, fertility, and cytology. Crop Sci. 13:36-39.

Owczarzak, A. 1952. A rapid method for mounting pollen grains. Stain Technol. 27:249.

Ronald, W.G. 1974. Genetic and high temperature control of self compatibility in Chrysanthemum morifolium Ramat. PhD diss., Univ. of Minn., St. Paul.

Ruiz T. and M.T.K. Arroyo. 1978. Plant reproductive ecology of a secondary deciduous tropical forest in Venezuela. Biotropica 10:221-230.

Soltis, D.E. 1986. Isozyme number and enzyme compartmentalization in Equisetum. Amer. J. Bot. 73:908-913.

Stephenson, A.G. and R.I. Bertin. 1983. Male competition, female choice and sexual selection in plants, p. 109-149. In: L.E. Real (ed.). Pollination biology. Academic Press, New York.

Taylor, N.L., K. Johnston, M.K. Anderson, and J.C. Williams. 1970. Inbreeding and heterosis in red clover. Crop Sci. 10:522-525.

U.S. Department of Agriculture. 1999. Floriculture crops-1998 summary. USDA, Natl. Agr. Stat. Serv., Wash., D.C.

Watanabe, K. 1977a. The control of diploid-like meiosis in polyploid taxa of Chrysanthemum (Compositae). Jpn. J. Genet. 52:125-131.

Watanabe, K. 1977b. Successful ovary culture and production of $F_{1}$ hybrids and androgenic haploids in Japanese Chrysanthemum species. J. Hered. 68:317320.

Winsor, J.A., L.E. Davis, and A.G. Stephenson. 1987. The relationship between pollen load and fruit maturation and the effect of pollen load on offspring vigor in Cucurbita pepo. Amer. Nat. 129:643-656.

Wolff, K., J. Peters Van Rijn, and H. Hofstra. 1994. RFLP analysis in chrysanthemum. I. Probe and primer development. Theor. Appl. Genet. 88:472-478.

Zagorski, J.S., P.D. Ascher, and R.E. Widmer. 1983. Multigenic self incompatibility in hexaploid Chrysanthemum. Euphytica 32:1-7. 